
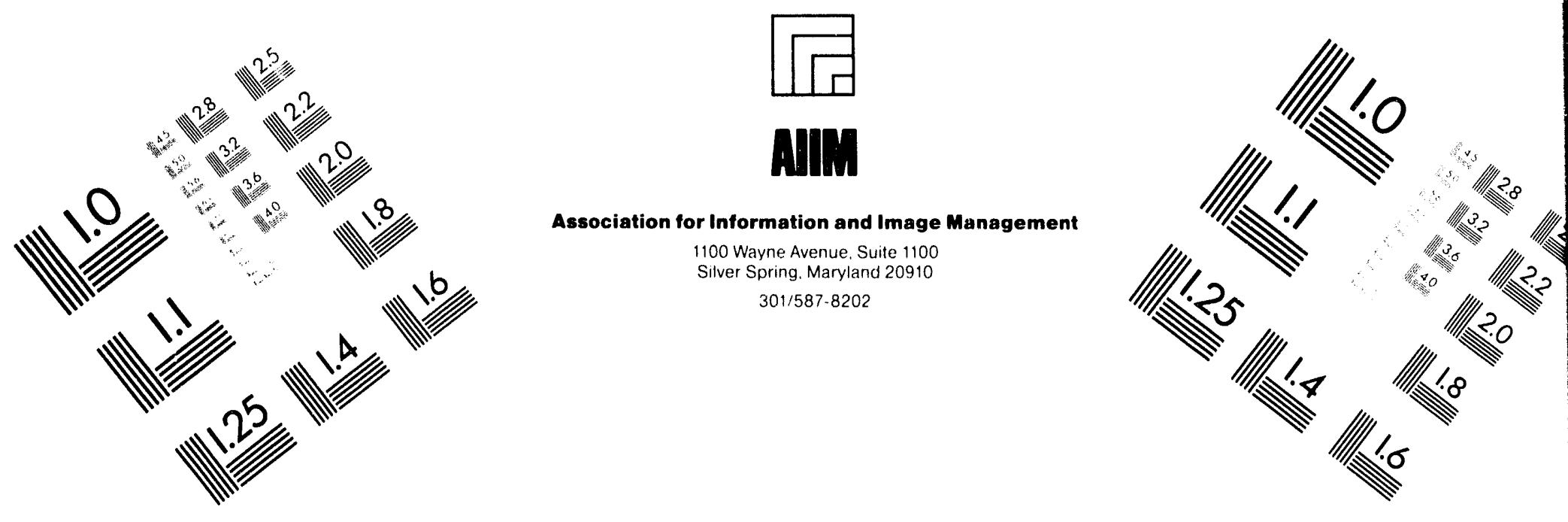

\title{
Centimeter
}

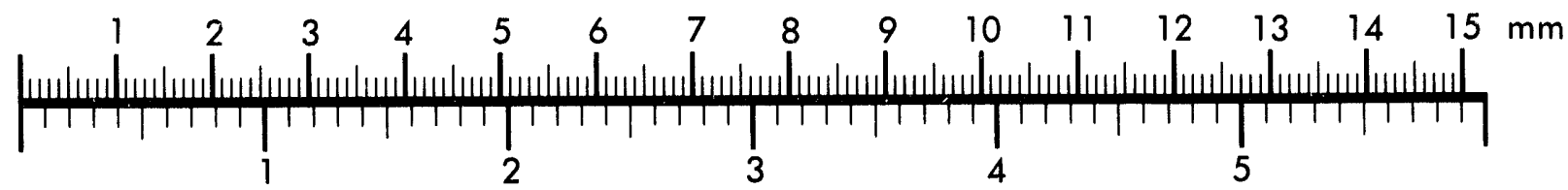

Inches
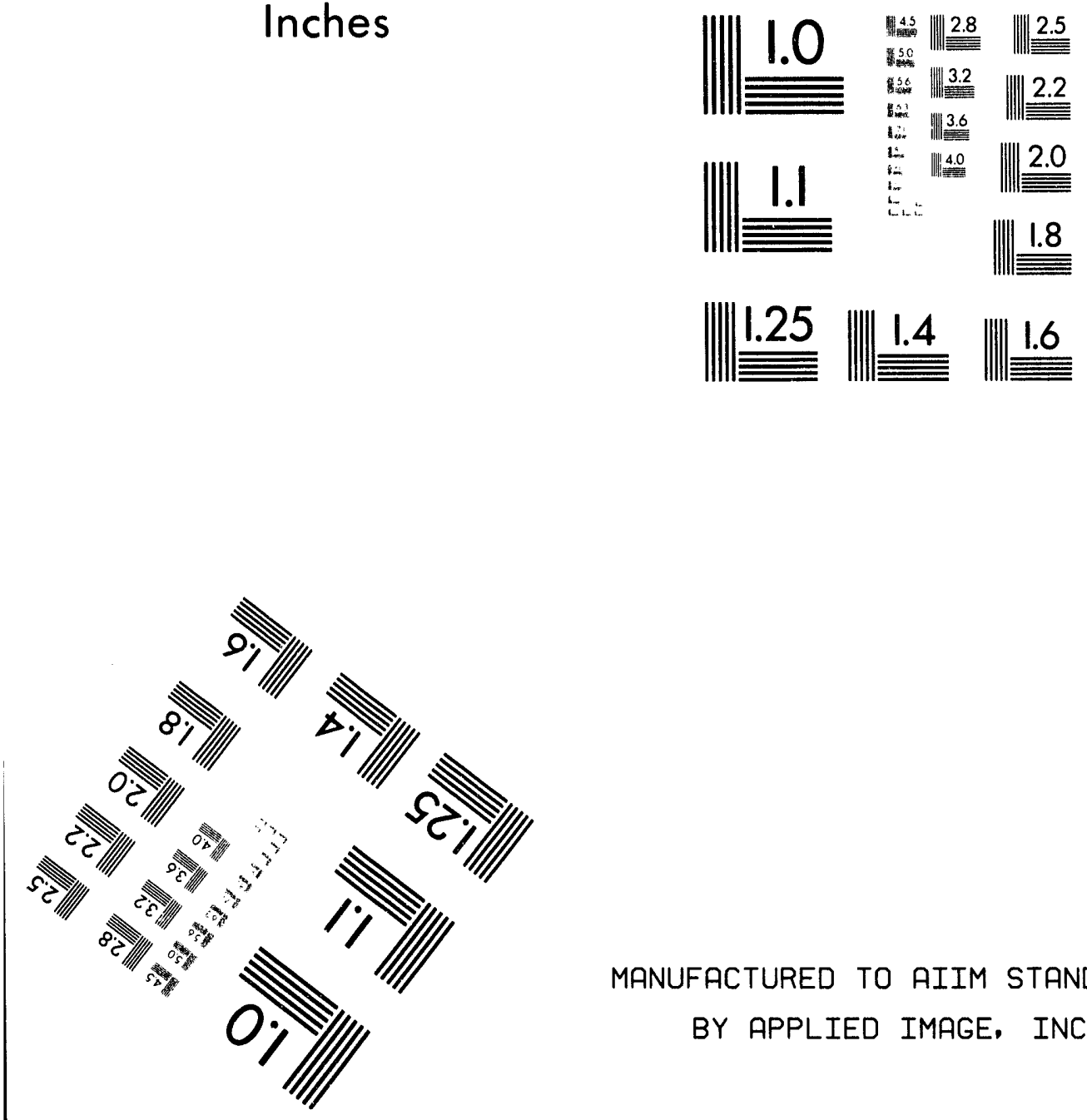

MANUFACTURED TO AIIM STANDARDS

BY APPLIED IMAGE, INC.

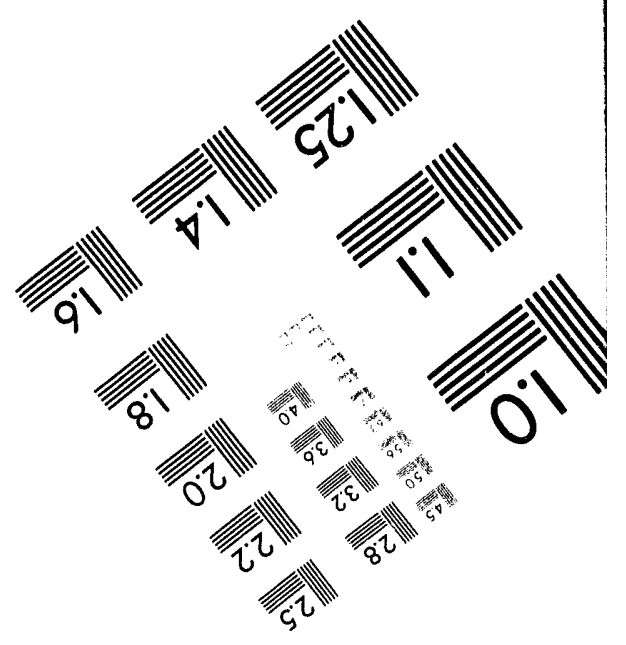



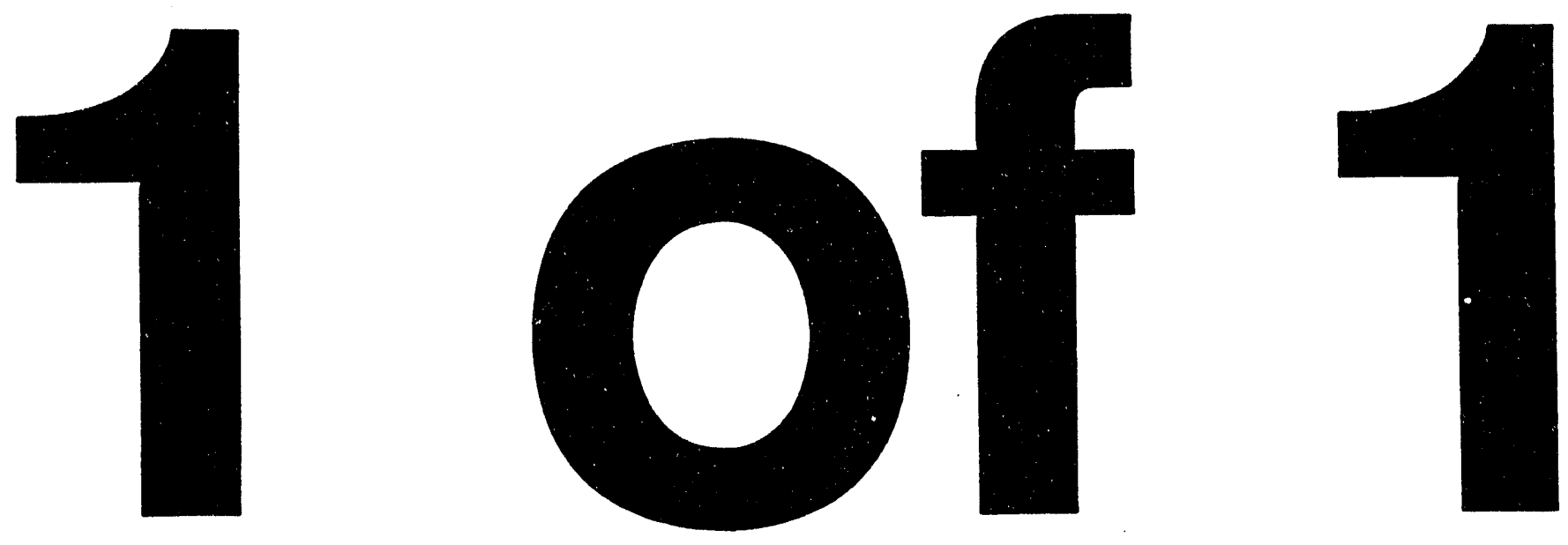


\section{H EVAPORATOR CP CLASS INSTRUMENTATION UNCERTAINTIES EVALUATIONS}

by

Hwang, E.

Westinghouse Savannah River Company

Savannah River Site

Aiken, South Carolina 29808

This paper was prepared in connection with work done under the above contract number with the U. S. Department of Energy. By acceptance of this paper, the publisher and/or recipient acknowledges the U.S. Government's right to retain a nonexclusive, royalty-free license in and to any copyright covering this paper, along with the right to reproduce and to authorize others to reproduce all or part of the copyrighted paper.

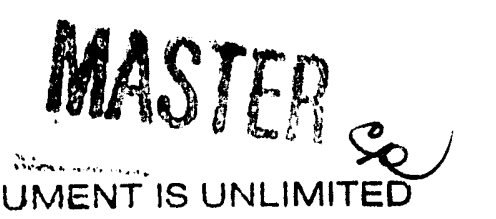




\section{DISCLAIMER}

This report was prepared as an account of work sponsored by an agency of the United States Government. Neither the United States Government nor any agency thereof, nor any of their employees, makes any warranty, express or implied, or assumes any legal liability or responsibility for the accuracy, completeness, or usefulness of any information, apparatus, product, or process disclosed, or represents that its use would not infringe privately owned rights. Reference herein to any specific commercial product, process, or service by trade name. trademark, manufacturer, or otherwise does not necessarily constitute or imply its endorsement, recommendation, or favoring by the United States Government or any agency thereof. The views and opinions of authors expressed herein do not necessarily state or reflect those of the United States "Government or any agency thereof.

This report has beea reproduced directly from the best available copy.

Available to DOE and DOE contractors from the Office of Scientific and Technical Information, P. O. Box 62. Oak Ridge. TN 37831: prices available from (615) 576-8401.

Available to the public from the National Technical Information Service. U. S. Deparment of Commerce, S285 Port Royal Rd., Springfield. VA 22161 
WSRC-TR-94-050 Rev. 0

Page 1 of 26

HIGH LEVEL WASTE ENGINEERING

H-TANK FARM COGNIZANT ENGINEERING SECTION

\author{
KEYWORDS: \\ Tank Farm \\ Evaporator \\ Instrument \\ Calibration \\ Uncertainty \\ RETENTION: \\ Permanent \\ CLASSIFICATION: \\ R.C.Aegege Aer. Enemen avioting \\ Authorized berivative Clasifitier \\ SR - 1C-50, Rore
}

\title{
2H EVAPORATOR \\ CP CLASS INSTRUMENTATION UNCERTAINTIES EVALUATIONS (U)
}

ISSUED: February 10, 1994

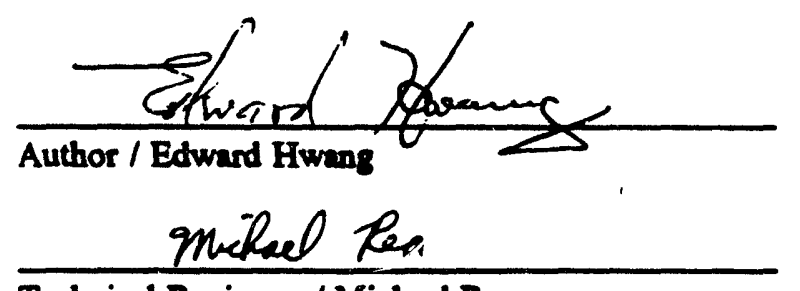

Technical Roviower / Michael Rea

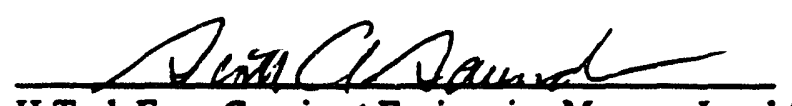

H-Tenk Farm Cognizant Engineering Menager Level 5 Scott Sumders

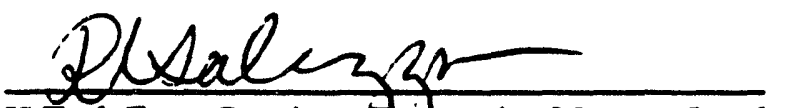

H-Tank Farm Cognizant Anglocering Manager Level 4 Richard Salizzoni
Date: $2 / 3 / 94$

Date $2 / 8 / 94$

Date: $z / 8 / 94$

Date: $2 / 8 / 4 \mathrm{c} /$ 
WSRC-TR-94-050 Rev. 0

Page 2 of 26

TABLE OF CONTENTS

Page

INTRODUCTION 3

Fig. 1 2H Evaporator Pot Temperature Instrumentation Loop 3

Fig. 2 2H Evaporator Condensate Gamma Monitor Instrumentation Loop 4

SUMMARY 5

Table 1 Evaporator Pot Temperature Loop Uncertainties Summary 5

Table 2 Condensate Gamma Monitor Loop Uncertainties Summary 6

METHODOLOGY

$\begin{array}{lc}\text { REFERENCE } & 8\end{array}$

1. EVAPORATOR POT TEMPERATURE INSTRUMENTATION LOOP 9

1.1 Temperature High Alarm \& Interlock Circuit 9

1.1.1 Measurement Uncertainties 9

1.1.2 Channel Statistical Allowance 11

1.1.3 Reference Document 11

1.2 Temperature Recorder Circuit 12

1.2.1 Measurement Uncertainties 12

1.2.2 Channel Statistical Allowance 13

1.2.3 Reference Document 14

2. CONDENSATE GAMMA MONTTOR INSTRUMENTATION LOOP 15

2.1 High Gamma Alarm \& Interlock Circuit 15

2.1.1 Measurement Uncertainties 15

2.1.2 Channel Statistical Allowance 17

2.1.3 Reference Document 17

2.2 Gamma Monitor Failure Alarm \& Interlock Circuit 18

2.2.1 Measurement Uncertainties 18

2.2.2 Channel Statistical Allowance 20

2.2.3 Reference Document 20

2.3 Cesium Activity Recorder Circuit 21

2.3.1 Measurement Uncertainties 21

2.3.2 Channel Statistical Allowance 22

2.3.3 Reference Document 23

2.4 Americium Activity Recorder Circuit 24

2.4.1 Measurement Uncertainties 24

2.4.2 Channel Statistical Allowance 25

2.4.3 Reference Document 26 


\section{Evaporntor CP Class Instrumentation Uncertainties Evaluations}

\section{INTRODUCTION}

There are two instrumentation systems in the $2 \mathrm{H}$ Evaporator facilities (bldg. $242-16 \mathrm{H}$ ) that are classified as the Critical Protection (CP) per technical report WSRC-TR-93-439, High Level Waste Facilities Intermediate Functional Classification. (1] They are the Evaporator Pot Temperature Instrumentations and the Steam Condensate Gamma Monitor.

The Evaporator Pot Temperature Instrumentation Loop 5028 (old loop \#1180) is illustrated in the loop diagram, Figure 1. ${ }^{[0]}$

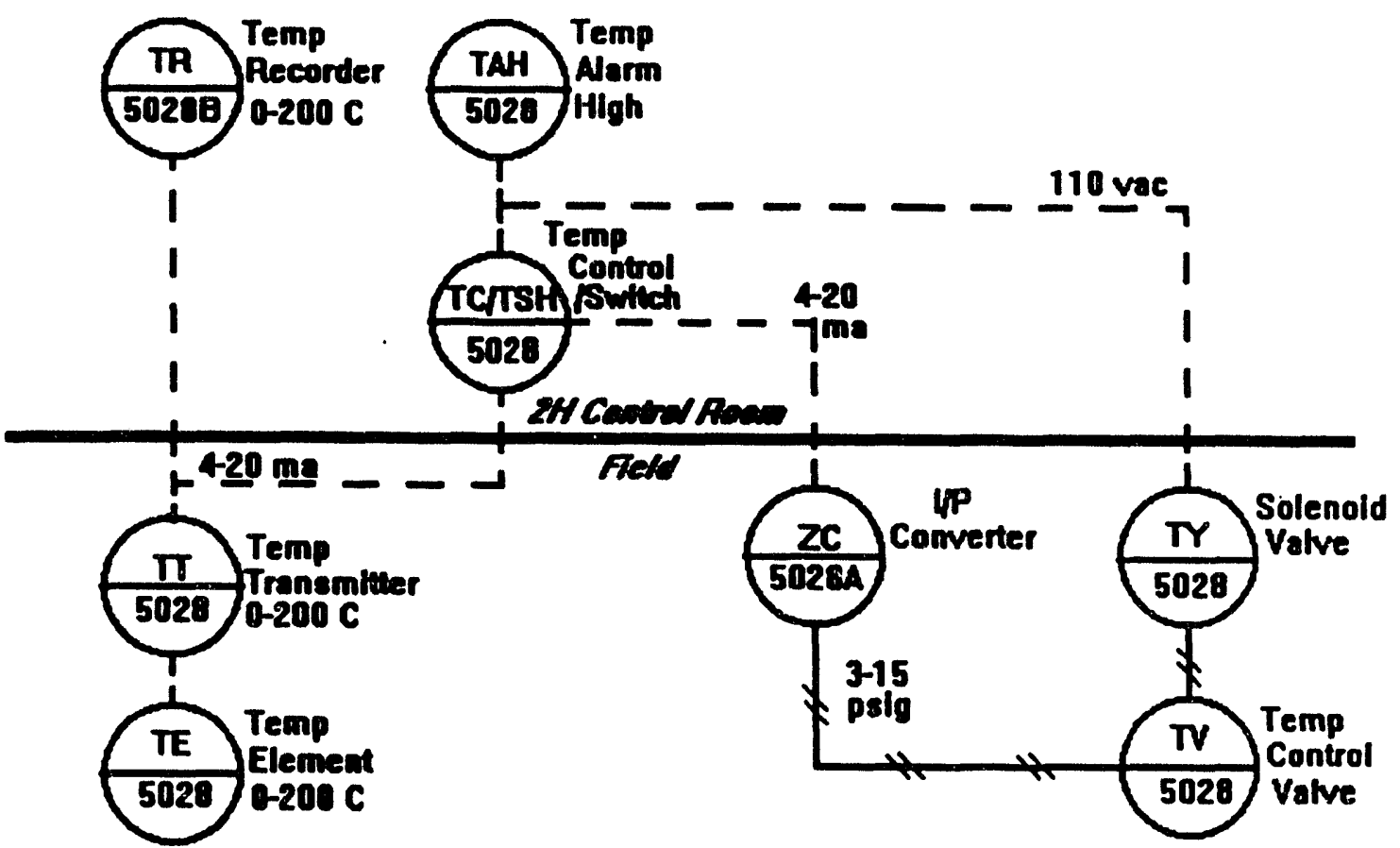

Fig. 1 2H Evanornor Pot Temperature Instrumentation Loog

The pot temperature instrumentation consists of two inter-related circuits sharing the same temperature sensor and transducer. They are:

1) Evaporator Pot Temperature High Alarm \& Interlock Circuit - It provides an annunciator alarm in the control room and triggers the trip solenoid of the steam control valve to shutoff the steam supply to the evaporator tube bundle.

2) Evaporator Pot Temperature Recorder Circuit - It provides the temperature reading and the stripchart recording in the control room.

The temperature control circuit is also shown in the above loop diagram. 
The Steam Condensate Gamma Monitor Instrumentation Loop 2022 (old loop \#1282) is illustrated in the loop diagram, Figure $2 .{ }^{[7]}$

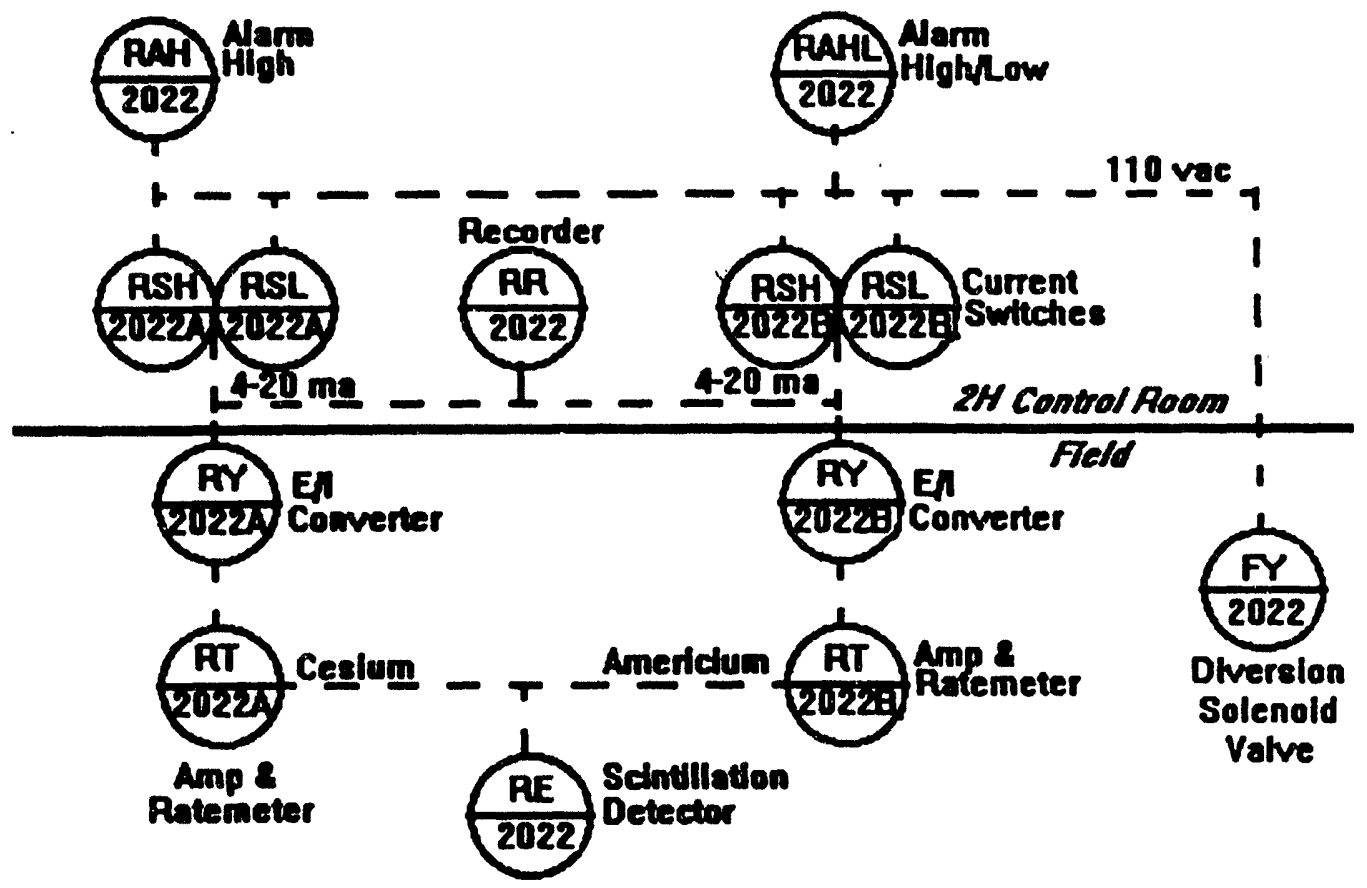

Fig. 2 2H Evaperator Condensatte Gamma Monitor lnstamentatten Loes

The gamma monitor instrumentation consists of four inter-related circuits sharing the same scintillation detector. They are:

1) Condensate High Gamma Alarm \& Interlock Circuit - It provides an annunciator alarm in the control room and triggers the condensate diversion valve solenoid.

2) Condensate Gamma Monitor Failure Alarm \& Interlock Circuit - It provides an annunciator alarm in the control room and triggers the condensate diversion valve solenoid.

3) Condensate Cesium Activity Recorder Circuit - It provides the condensate Cesium activity reading and the stripchart recording in the control room.

4) Condensate Americium Activity Recorder Circuit - It provides the condensate Americium activity reading and the stripchart recording in the control room.

The channel measurement uncertainty for each instrument circuit is evaluated in detail. The methodology used in the SRS K-Reactor Safety-Related Instrumentation Setpoint Uncertaintie Evaluations, WSRC-TR-91-0167[2], is applied for this evaluation and is highlighted in the METHODOLOGY section.

The resulting uncertainties for the two loops are tabulated in the SUMMARY section.

The evaluation details for each instrument circuit are described in sections 1 and 2 . 


\section{SUMMARY}

The resulting uncertainties for the evaporator pot temperature instrument circuits are tabulated in the following Summary Table 1. The field M\&TE accuracy is assumed to be 1:1 ratio or better than the process instrument calibration accuracy. The uncertainty figure needs to be revised upward if the accuracy is worse than 1:1 ratio.

TABLE 1 Evaporator Pot Temoerature Loop Uncertainties Summary

\begin{tabular}{|c|c|c|c|c|c|}
\hline 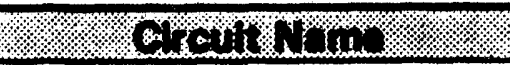 & $8000 \mathrm{~m}$ & E. OU. & Therow & $\cos \alpha 2$ & Celib, Span \\
\hline \multicolumn{6}{|l|}{ (1) 2H Evaporator Loop 5028} \\
\hline Pot Tomperature High Alarm & 150 & Deg C & 4.3 & 2.17 & 200 Deg C \\
\hline \multicolumn{6}{|l|}{ Circuit } \\
\hline (2) $2 \mathrm{H}$ Evaporator Loop 5028 & & & & & \\
\hline Pot Tomperature Recorder & N/A & Deg C & 5.8 & 2.89 & $200 \mathrm{Deg} C$ \\
\hline Circuit & & & & & \\
\hline
\end{tabular}

The Pot Temperature High Alarm Circuit has an overall channel statistical allowance (CSA) of $2.17 \%$ over the calibrated span of 200 degrees C, namely, an instrument uncertainty of 4.3 degrees $C$. Thus, the evaporator inlet steam automatic shutoff setpoint of 150 degrees $C$ has a built-in safety margin of at least 5.7 degrees $C$ before the pot temperature will reach the OSR Limit of 160 degrees C. The circuit details along with its components are described in Section 1.1; all specified/assigned measurement uncertainty terms are explained in Section 1.1.1; the overall channel statistical allowance and the instrument circuit uncertainties are calculated in Section 1.1.2; all the reference materials are listed in Section 1.1.3.

The Pot Temperature Recorder Circuit has an overall channel statistical allowance (CSA) of 2.89 \% over the calibrated span of 200 degrees C, namely, an instrument uncertainty of 5.8 degrees $C$. The circuit details along with its components are described in Section 1.2; all specified/assigned measurement uncertainty terms are explained in Section 1.2.1; the overall channel statistical allowance and the instrument circuit uncertainties are calculated in Section 1.2.2; all the reference materials are listed in Section 1.2.3.

The resulting uncertainties for the condensate gamma monitor instrument circuits are tabulated in the Summary Table 2, next page. The field M\&TE accuracy is assumed to be 1:1 ratio or better than the process instrument calibration accuracy. The uncertainty figure needs to be revised upward if the accuracy is worse than 1:1 ratio.

The Condensate High Gamma Alarm Circuit has an overall channel statistical allowance (CSA) of $7.38 \%$ over the calibrated span of $100 \%$, namely, an instrument uncertainty of $7.4 \%$. Though the alarm setpoint is yet to be determined by HP, the SRS instrumentation practice of using a $10 \%$ error allowance for the radiation monitor reading has a built-in safety magin of $2.6 \%$. The circuit details along with its components are described in Section 2.1; all specified/assigned measurement uncertainty terms are explained in Section 
WSRC-TR-94-050 Rev. 0

Page 6 of 26

2.1.1; the overall channel statistical allowance and the instrument circuit uncertainties are calculated in Section 2.1.2; all the reference materials are listed in Section 2.1.3.

TABLE 2 Condensate GAMMA Monitor Loop Uncertainties Summarx

\begin{tabular}{|c|c|c|c|c|c|}
\hline (1) 2H Evaporator Loop 2022 & & & & & \\
\hline Condensate High Gamma & N/A & $\%$ & 7.4 & 7.38 & $100 \%$ \\
\hline Alarm Circuit & & & & & \\
\hline \hline (2) 2H Evaporator Loop 2022 & & & & & \\
\hline Condensate Gamma Monitor & N/A & $\%$ & 7.4 & 7.38 & $100 \%$ \\
\hline Failure Alarm Circuit & & & & & \\
\hline (3) 2H Evaporator Loop 2022 & & & & & \\
\hline Condensate Cesium Activity & N/A & $\%$ & 7.6 & 7.57 & $100 \%$ \\
\hline Recorder Circuit & & & & & \\
\hline (4) 2H Evaporator Loop 2022 & & & & & \\
\hline Condensate Americium & N/A & $\%$ & 7.6 & 7.57 & $100 \%$ \\
\hline Activity Recorder Circuit & & & & & \\
\hline \hline
\end{tabular}

The Condensate Gamma Monitor Failure Alarm Circuit has an overall channel statistical allowance (CSA) of $7.38 \%$ over the calibrated span of $100 \%$, namely, an instrument uncertainty of $7.4 \%$. The circuit details along with its components are described in Section 2.2; all specified/assigned measurement uncertainty terms are explained in Section 2.2.1; the overall channel statistical allowance and the instrument circuit uncertainties are calculated in Section 2.2.2; all the reference materials are listed in Section 2.2.3.

The Condensate Cesium Activity Recorder Circuit has an overall channel statistical allowance (CSA) of $7.57 \%$ over the calibrated span of $100 \%$, namely, an instrument uncertainty of $7.6 \%$. The circuit details along with its components are described in Section 2.3; all specified/assigned measurement uncertainty terms are explained in Section 2.3.1; the overall channel statistical allowance and the instrument circuit uncertainties are calculated in Section 2.3.2; all the reference materials are listed in Section 2.3.3.

The Condensate Americium Activity Recorder Circuit has an overall channel statistical allowance (CSA) of $7.57 \%$ over the calibrated span of $100 \%$, namely, an instrument uncertainty of $7.6 \%$. The circuit details along with its components are described in Section 2.4; all specified/assigned measurement uncertainty terms are explained in Section 2.4.1; the overall channel statistical allowance and the instrument circuit uncertainties are calculated in Section 2.4.2; all the reference materials are listed in Section 2.4.3. 


\section{METHODOLOGY}

The channel statistical allowance (CSA) for each instrument circuit is calculated using USNRC approved Westinghouse method ${ }^{[2]}$ of applying the square-root-of-the-sum-ofsquares (SRSS) combination of the measurement uncertainties. The SRSS method is also adopted by the Instrument Society of America Standard S67.04-1987, Setpoints for Nuclear Safety-Related Instrumentation. [3]

$$
\begin{aligned}
& C S A=\sqrt{P M A^{2}+P E A^{2}+S A^{2}+S T E^{2}+S P E^{2}+R A^{2}+R T E^{2}}+E A+B I A S \\
& S A=\sqrt{\left(S C A_{1}+S M T E_{1}+S D_{1}\right)^{2}+\left(S C A_{2}+S M T E_{2}+S D_{2}\right)^{2}+\left(S C A_{3}+S M T E_{3}+S D_{3}\right)^{2}} \\
& R A=\sqrt{R A_{1}^{2}+R A_{2}^{2}+R A_{3}^{2}} \\
& R A_{1}=R C A_{1}+R C S A_{1}+R M T E_{1}+R D_{1} \\
& R A_{2}=R C A_{2}+R C S A_{2}+R M T E_{2}+R D_{2} \\
& R A_{3}=R C A_{3}+R C S A_{3}+R M T E_{3}+R D_{3} \\
& \text { Uncertainty }=\operatorname{Span} \times(C S A / 100)
\end{aligned}
$$

The measurement uncertainty terms used in the calculations are defined in the SRS Report WSRC-TR-91-0167 ${ }^{(2]}$ that were derived from ISA Std S67.04-1987 ${ }^{[3]}$, ANSI/ASME Std PTC19.1-1985 ${ }^{[4]}$, and SAMA Std PMC20.1-1973. ${ }^{[S]}$

- PMA - Process Measurement Accuracy

PMA is a non-device related error that is inherent with the process measurement method.

- PEA - Primary Element Accuracy

PEA is the error due to any use of metering device (e.g., ventun, orifice, elbow, etc.) to affect the process medium to obtain the parameter readings.

- SA - Sensor Allowance

SA is the combined sensor error allowance for SCA, SMTE, \& SD terms.

- SCA - Sensor Calibration Accuracy

SCA is the error tolerance of the sensor that includes the combined effects of hysteresis, deadband, linearity, and repeatability.

- SMTE - Sensor Measurement \& Test Equipment accuracy

SMTE is the error tolerance of the test equipment used to calibrate the sensor in the instrument lab.

- SD - Sensor Drift

SD is the error due to gradual change over time between calibrations in the sensor output from the original calibrated settings.

- STE - Sensor Temperature Effect

STE is any deviation in sensor input-output relationship due to ambient temperature changes from the reference calibration conditions. 
- SPE - Sensor Pressure Effect

SPE is any deviation in sensor input-output relationship due to static head pressure changes from the reference calibration conditions.

- RA - Rack Allowance

RA is the combined rack error allowance for RCA, RCSA, RMTE, \& RD terms.

- RCA - Rack Calibration Accuracy

RCA is the error tolerance of the process rack circuit that includes the combined effects of hysteresis, deadband, linearity, and repeatability.

- RCSA - Rack Comparator Setting Accuracy

RCSA is the calibration error tolerance of the bistable module in the process rack.

- RMTE - Rack Measurement \& Test Equipment accuracy

RMTE is the error tolerance of the test equipment used to calibrate the process rack in the field.

- RD - Rack Drift

RD is the error due to gradual change over time between calibrations in the process rack output from the original calibrated settings.

- RTE - Rack Temperature Effect

RTE is any deviation in input-output relationship for the process rack module string due to changes in ambient temperature from the reference calibration conditions.

- EA - harsh Environmental Allowance

EA is any deviation in process measurement output (sensor and process rack) due to adverse environmental conditions from a limiting accident, such as:

- radiation effect on sensor,

- seismic effects on sensor and process rack, and

- high temperature effects on signal cable insulation.

- BIAS

BIAS is any known existing unidirectional effect to the measured process parameter.

\section{REFERENCE}

[1] SRS Report WSRC-TR-93-439 Rev 0, High Level Waste Facilities Intermediate Eunctional Classification.

[2] SRS Report WSRC-TR-91-0167 Rev 0, SRS K-Reactor Instrumentation Setpoint Uncertainties Evaluation.

[3] Instrument Society of America (ISA) Std S67.04-1987, Setpoint for Nuclear SafetyBelated Instrumentation.

[4] American National Standard Institute (ANSI/ASME) Std PTC19.1-1985, Measurement Uncertainty.

[5] Scientific Apparatus Makers of America (SAMA) Std PMC20.1-1973, Process Measurement \& Control Terminology.

SRS Drawings:

[6] M-M6-H-8339 Rev. 0, Evaporator Instrumentation Pipine Diagram.

[7] M-M6-H-7849 Rev. 0, 2H Evaporator Steam System Piping Diagram. 
WSRC-TR-94-050 Rev. 0

Page 9 of 26

\section{EVAPORATOR POT TEMPERATURE INSTRUMENTATION LOOP}

\subsection{Temperature Hieh Alarm \& Interlock Circuit}

The high temperature alarm circuit in the evaporator control room is to alert the operator when the pot temperature exceeds 150 degrees $C$ that is the operating limit for the evaporator. The alarm circuit, referring to Fig. 1 loop diagram, consists of the temperature element TE-5028, the temperature transmitter TT-5028, the temperature controller/switch TC/TSH-5028 connecting to an interposing relay that is wired to the annunciator window TAH-5028 and the solenoid valve actuator TY-5028. [S,6] Except for the sensor, the remainder of the circuit constitutes the process rack in the uncertainty evaluations.

- Temperature Element: Type J Thermocouple for 0-200 degrees C.

- Temperature Transmitter: HY-CAL Model CT-865-C Millivolts/Current Transmitter - calibrated to 4-20 ma for 0-200 deg C. [J]

- Temp Controller/Switch: MOORE Model 352E Control/Alarm Unit - calibrated to activate the switch at $4 \mathrm{vdc}$ (16 ma across a 250 ohms resister) increasing electrical signal corresponding to 150 degrees $C$ evaporator pot temperature. [4]

- Interposing Relay \& Panel Annunciator "EVAP POT HI TEMP".(4)

The high alarm circuit is calibrated for 0 to 200 degrees $\mathrm{C}$ pot temperature span. The temperature transmitter, in a NEMA-4 enclosure by the evaporator building $242-16 \mathrm{H}$, receives the thermocouple input from a thermowell tap on the evaporator cover. The current signal output from the transmitter is routed to the current switch located at the rear of the control panel in the control room bldg. 241-28H. 66.7$]$ The energizing contact signal from the interposing relay is connected to the annunciator window on the control panel and to the trip solenoid of the inlet steam control valve for the evaporator tube bundle.

\subsubsection{Measurement Uncertainties - in \% of calibrated span}

Process Measurement Accuracy (PMA $=1.0 \%$ )

A 2 degree $C$ is assigned for the process measurement error to take into account the hot spot uncertainties influenced by uneven temperature gradiations or stratifications in the evaporator pot.

Primary Element Accuracy (PEA $=0.25 \%$ )

The effect of thermowell to the thermocouple is assigned to be 0.5 degree $C$.

Sensor Calibration Accuracy ( $\mathrm{SCA}=0.5 \%)$

The error tolerance for the thermocouple is $0.5 \%$ per vender device performance specificatiors. 
Sensor Measurement \& Test Equipment (SMTE $=0.5 \%$ )

The standards lab M\&TE to the field M\&TE accuracy ratio will meet the IEEE Std 4981980(1) requirements of 4:1[2]. Therefore, the accuracy of the standards lab M\&TE can be ignored and the uncertainty for the field M\&TE can be set based on the 1:1 ratio of the field M\&TE to process instrument calibration accuracy.

Sensor Drift (SD $=0.3 \%)$

The sensor stability is $0.3 \%$ per year per vender device performance specifications.

Sensor Temperalure Effect (STE $=0 \%$ )

The ambient temperature effect is negligible.

Sensor Pressure Effect (SPE = 0 \%)

The ambient static pressure has negligible effect on the sensor.

Rack Calibration Accuracy ( $R C A=0.35 \%$ )

The error tolerance for HY-CAL transmitter is $0.35 \%$ per vendor device performance specifications.[?]

Rack Comparator Setting Accuracy (RCSA $=0.1 \%$ )

The error tolerance for MOORE controller/switch is $0.1 \%$ per vendor device performance specifications. [?]

Rack Measurement \& Test Equipment

$\left(\mathrm{RMTE}_{1}=0.35 \%, \mathrm{RMTE}_{2}=0.1 \%\right.$ )

The uncertainty for the field M\&TE is set based on the 1:1 ratio of the field M\&TE to

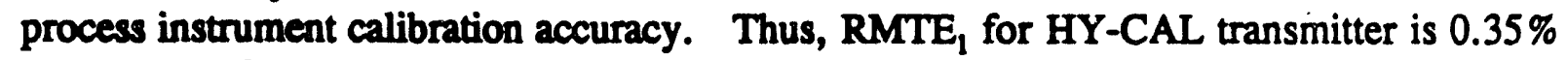
and RMTE for MOORE controller/switch is $0.1 \%$.

Rack Drift $\left(R D_{1}=0.3 \%, R_{2}=0.3 \%\right)$

$R D_{1}$ for HY-CAL transmitter is $0.3 \%$ and $R D_{2}$ for MOORE controller/switch is $0.3 \%$ per vendor device performance specifications.

Rack Temperature Effect $\left(\mathrm{RTE}_{1}=0.66 \%, \mathrm{RTE}_{2}=0.5 \%\right)$

RTE $_{1}$ for HY-CAL transmitter is $0.66 \%$ and RTE $_{2}$ for MOORE controller/switch is $0.5 \%$ per vendor device performance specifications.

harsh Environmental Allowance (EA $=0 \%)$

The circuit is not subject to harsh environment.

BIAS - $0 \%$

No known bias exists. 


\subsubsection{Channel Statistical Allowance}

The channel statistical allowance and the measurement uncertainties for the evaporator pot high temperature alarm circuit are:

$$
\begin{aligned}
C S A & =\sqrt{1^{2}+25^{2}+(5+5+3)^{2}+0+0+(35+0+35+3)^{2}+(0+.1+.1+.3)^{2}+.66^{2}+5^{2}}+0+0 \\
& =2.165 \%
\end{aligned}
$$

Uncertainty $=200 \times(2.165 / 100)=4.33$ degrees $C$

The resulting CSA is $2.165 \%$ of the calibrated span of 200 degrees C, namely, the instrument uncertainty for the high temperature alarm circuit is 4.33 degrees $C$.

\subsubsection{Reference Document}

[1] IEEE Std 498-1980, Calibration and Control of Measuring \& Test Equipment Used in Nuclear Power Generation Stations.

[2] SRS Quality Assurance Manual 1Q Procedure QAP 12-1 4/1/90, Control of Measuring and Test Equipment.

SRS HIWWM Procedures:

[3] \#14347 Rev. 1, Verification/Calibration of HY-CAL Temperature Transmitter.

[4] \#14433 Rev. 1, Verification/Calibration of MOORE 353E Controller/Alarm Unit.

[5] \#17027 Rev. 1, Loop Verification for 2H Evaporator Pot Temperature Loop 1180. SRS Drawings:

[6] M-M6-H-8339 Rev. 0, Evaporator Instrumentation Piping Diagram.

[7] W-701062 Rev. 100, Bldg, 242-16H Eyaporator Piping Diagram. Vendor Literature:

[8] HY-CAL Engineering Manual, Thermocouple/Cument Transmitter Model CT-865C.

[9] MOORE Industries Manual, Controller/Alarm Unit Model 352E. 


\subsection{Temperature Recorder Circuit}

The pot temperature recorder circuit in the evaporator control room is to provide the temperature readings and stripchart recordings for the operator. The recorder circuit, referring to Fig. 1 loop diagram, consists of the temperature element TE-5028, the temperature transmitter TT-5028, and the stripchart recorder TR-5028B.[5,0] Except for the sensor, the remainder of the circuit constitutes the process rack in the uncertainty evaluations.

- Temperature Element: Type J Thermocouple for 0-200 degrees C.

- Temperature Transmitter: HY-CAL Model CT-865-C Millivolts/Current Transmitter - calibrated to 4-20 ma for 0-200 deg C. (3)

- Temperature Recorder: LEEDS \& NORTHRUP Speedomax 430 Series - calibrated to 0-200 deg. C for 4-20 ma. ${ }^{[4]}$

The recorder circuit is calibrated for 0 to 200 degrees C pot temperature span. The temperature transmitter, in a NEMA-4 enclosure by the evaporator building $242-16 \mathrm{H}$, receives the thermocouple input from a thermowell tap on the evaporator cover. The current signal output from the transmitter is routed to the stripchart recorder located on the control panel in the control room bldg. 241-28H..$^{[6, \pi]}$

\subsubsection{Measurement Uncertainties - in \% of calibrated span}

Process Measurement Accuracy (PMA $=1.0 \%$ )

A 2 degree $C$ is assigned for the process measurement error to take into account the hot spot uncertainties influenced by uneven temperature gradiations or stratifications in the evaporator pot.

Primary Element Accuracy (PEA $=0.25 \%)$

The effect of thermowell to the thermocouple is assigned to be 0.5 degrees $\mathrm{C}$.

Sensor Calibration Accuracy (SCA $=0.5 \%$ )

The error tolerance for the thermocouple is $0.5 \%$ per vender device performance specifications.

Sensor Measurement \& Test Equipment (SMTE $=0.5 \%$ )

The standards lab M\&TE to the field M\&TE accuracy ratio will meet the IEEE Std 4981980(1) requirements of 4:1[2]. Therefore, the accuracy of the standards lab M\&TE can be ignored and the uncertainty for the field M\&TE can be set based on the 1:1 ratio of the field M\&TE to process instrument calibration accuracy.

Sensor Drift (SD $=0.3 \%)$

The sensor stability is $0.3 \%$ per year per vender device performance specifications. 
Sensor Temperature Effect (STE $=0 \%$ )

The ambient temperature effect is negligible.

Sensor Pressure Effect (SPE = 0 \%)

The ambient static pressure has negligible effect on the sensor.

Rack Calibration Accuracy $\left(\mathrm{RCA}_{1}=0.35 \%, \mathrm{RCA}_{2}=0.7 \%, \mathrm{RCA}_{3}=1.0 \%\right)$

$\mathrm{RCA}_{1}$ for the HY-CAL transmitter is $0.35 \%$ and $\mathrm{RCA}_{2}$ for $\mathrm{L} \& \mathrm{~N}$ recorder is $0.7 \%$ per vendor equipment specifications. ${ }^{[8,9]}$ In addition, a 2 degree $C$ is assigned to the chart reading error allowance $\mathrm{RCA}_{3}$ (one half of the smallest chart scale).

Rack Comparator Setting Accuracy (RCSA $=0$ \%)

There is no bistable element in the recorder circuit.

Rack Measurement \& Test Equipment (RMTE $1=0.35 \%, \mathrm{RMTE}_{2}=0.7 \%$ )

The uncertainty for the field M\&TE is set based on the 1:1 ratio of the field M\&TE to process instrument calibration accuracy. Thus, RMTE 1 for HY-CAL transmitter is $0.35 \%$ and $\mathrm{RMTE}_{2}$ for $\mathrm{L} \& \mathrm{~N}$ recorder is $0.7 \%$.

Rack Drift $\left(\mathrm{RD}_{1}=0.3 \%, \mathrm{RD}_{2}=0.3 \%\right)$

$\mathrm{RD}_{1}$ for $\mathrm{HY}$-CAL transmitter is $0.3 \%$ and $\mathrm{RD}_{2}$ for $\mathrm{L} \& \mathrm{~N}$ recorder is $0.3 \%$ per vendor device performance specifications.

Rack Temperature Effect $\left(\mathrm{RTE}_{1}=0.66 \%, \mathrm{RTE}_{2}=0.5 \%\right)$

$\mathrm{RTE}_{1}$ for HY-CAL transmitter is $0.66 \%$ and $\mathrm{RTE}_{2}$ for $\mathrm{L} \& \mathrm{~N}$ recorder is $0.5 \%$ per vendor device performance specifications.

harsh Environmental Allowance $(E A=0 \%)$

The circuit is not subject to harsh environment.

BIAS - $0 \%$

No known bias exists.

\subsubsection{Channel Statistical Allowance}

The channel statistical allowance and the measurement uncertainties for the evaporator pot temperature recorder circuit are:

$$
\begin{aligned}
\operatorname{CSA} & =\sqrt{1^{2}+25^{2}+(5+5+3)^{2}+0+0+(35+0+35+3)^{2}+(.7+0+.7+3)^{2}+(1+0+0+0)^{2}+.66^{2}+5^{2}}+0+0 \\
& =2.886 \%
\end{aligned}
$$

Uncertainty $=200 \times(2.886 / 100)=5.77$ degrees C 
WSRC-TR-94-050 Rev. 0

Page 14 of 26

The resulting CSA is $2.886 \%$ of the calibrated span of 200 degrees C, namely, the instrument uncertainty for the temperature recorder circuit is 5.77 degrees $C$.

\subsubsection{Beference Document}

[1] IEEE Std 498-1980, Calibration and Control of Measurine \& Test Equipment Used in Nuclear Power Generation Sntions.

[2] SRS Quality Assurance Manual 1Q Procedure QAP 12-1 4/1/90, Control of Menqurine and Teat Equipment.

SRS HILWM Procedures:

[3] \#14347 Rev. 1, Yerification/Calibration of HY-CAL Temperature Transmitter.

[4] 14361 Rev. 1, Yerification/Calibration of L \& N 430 Recorder.

[5] 17027 Rev. 1, Loop Verification for 2H Evaporator Pot Temperature Loop 1180. SRS Drawings:

[6] M-M6-H-8339 Rev. 0, Evaporator Instrumentation Pipine Diacram.

[7] W-701062 Rev. 100, Blde. 242-16H Evaponator Biping Diagram. Vendor Literature:

[8] HY-CAL Engincering Manual, Thermocouple/Current Transmitter Model CT-865C.

[9] LEEDS \& NORTHRUP Manual, Model 430 Recorder. 
WSRC-TR-94-050 Rev. 0

Page 15 of 26

\section{CONDENSATE GAMMA MONITOR INSTRUMENTATION LOOP}

\subsection{Bioh Gamma Alarm \& Interlock Circuit}

The high gamma alarm circuit is to alert the operator that the gamma activity in the evaporator condensate exceeds the limit setting. It also automatically triggers the diversion valve to transfer the condensate to a waste storage tank for reprocessing. The alarm circuit, referring to Fig. 2 loop diagram, consists of the scintillation detector RE2022, the cesium discriminating amplifier \& ratemeter RT-2022A along with its associated E/I converter RY-2022A, the current switch RSH-2022A, and the annunciator high alarm plate RAH-2022. ${ }^{\circ}$ ] Except for the scintillation detector, the remainder of the circuit constitutes the process rack in the uncertainty evaluations.

- Scintillation Detector: HARSHAW/FILTROL MPF assembly with 2" $\times 6$ " crystal calibrated to 0-100\% from pre-set known solution. (7)

- Spectro-signal Amplifier \& Ratemeter: HARSHAW/FILTROL NA-23, NC-22, and NR-25 - calibrated to 0-10 mv for 0-100\%, [7,15]

- Millivolt/current Transmitter: ACROMAG Model 160T - calibrated to 4-20 ma for 010 mv. [0]

- Current Switch: MOORE Model DCA - calibrated to 0-100\% for 4-20 ma. ${ }^{[5]}$

- Annunciator High Alarm Plate "CONDENSATE HIGH ACTIVITY FLASH TANK".

The alarm circuit is calibrated for 0 to $100 \%$ of gamma activity span. The spectro-signal amplifier \& ratemeter, in a NEMA 4 enclosure by the evaporator building $242-16 \mathrm{H}$, receives the scintillation detector input from a monitor container housing on the condensate transfer pipings. The $E / I$ converter in the same enclosure converts the ratemeter $0-10 \mathrm{mv}$ output signal to 4-20 ma current signal and is wired to the high/low current switches located in the rear of the 1175B1 control panel in the control room bldg. 241-28H. The energizing contact signal from the interposing relay is connected to the annunciator high alarm plate on the control panel and to the diversion solenoid valve on the condensate transfer pipings. $[8,9,15]$

\subsubsection{Measurement Uncertainties - in \% of calibrated span}

Process Measurement Accuracy (PMA $=5 \%$ )

A $5 \%$ error tolerance is allowed in the SRS instrumentation practice. ${ }^{[4]}$

Primary Element Accuracy (PEA $=3 \%$ )

A $3 \%$ error allowance is assigned for the flow disturbance effect of the detector pot arrangement to the detector readings.

Sensor Calibration Accuracy ( $\mathrm{SCA}=0.5 \%$ )

The error tolerance is $0.5 \%$ per vendor device performance specifications. ${ }^{110,11]}$ 
Sensor Measurement \& Teat Equipment (SMTE $=0.5 \%$ )

The standards lab M\&TE to the field M\&TE accuracy ratio will meet the IEEE Std 4981980(1) requirements of 4:1[2]. Therefore, the accuracy of the standards lab M\&TE can be ignorei and the uncertainty for the field M\&TE can be set based on the 1:1 ratio of the field M\&TE to process instrument calibration accuracy.

Sensor Drift (SD $=0.5 \%)$

The sensor stability is $\mathrm{C.5 \%}$ error per year per vendor device performance specifications.

Sensor Temperature Effect (STE $=0 \%$ )

The ambient temperature has negligible effect on the sensor.

Sensor Pressure Effect (SPE $=0 \%$ )

The static pressure has negligible effect on the sensor.

Rack Calibration Accuracy $\left(\mathrm{RCA}_{1}=1.6 \% ; \mathrm{RCA}_{2}=0.1 \%\right)$

$\mathrm{RCA}_{1}$ for the amp \& ratemeter is $1.6 \%$ and $\mathrm{RCA}_{2}$ for the $\mathrm{E} / \mathrm{I}$ converter is $0.1 \%$ per vendor device performance specifications. $112,13,14,16]$

Rack Comparator Setting Accuracy (RCSA $=0.1 \%$ )

The error tolerance for the current switch is $0.1 \%$ per vendor device performance specifications. "17]

Rack M\&TE $\left(\operatorname{RMTE}_{1}=1.6 \% ; \mathrm{RMTE}_{2}=0.1 \%, \mathrm{RMTE}_{3}=0.1 \%\right)$

The uncertainty for the field M\&TE is set based on the 1:1 ratio of the field M\&TE to process instrument calibration accuracy.

Rack Drift $\left(R D_{1}=1.0 \%, R D_{2}=0.1 \%, R D_{3}=0.1 \%\right)$

$R D_{1}$ for the amp \& ratemeter is $1.0 \%, R_{2}$ for the $E / I$ converter is $0.1 \%$, and $R D_{3}$ for the current switch is $0.1 \%$ per vendor device performance specifications.

Rack Temperature Effect $\left(\mathrm{RTE}_{1}=0.5 \%, \mathrm{RTE}_{2}=0.3 \%\right)$

$\mathrm{RTE}_{1}$ for the ratemeter is $0.5 \%$, and $\mathrm{RTE}$, for the E/I converter is $0.3 \%$ per vendor device performance specifications.

harsh Environmental Allowance (EA $=0$ \%)

The circuit is not subject to harsh environment.

BIAS - $0 \%$

No known bias exists. 


\subsubsection{Channel Statistical Allowance}

The channel statistical allowance and the measurement uncertainties for the condensate high gamma alarm circuit are:

$$
\begin{aligned}
C S A & =\sqrt{5^{2}+3^{2}+(5+5+5)^{2}+0+0+(1.6+0+1.6+1)^{2}+(1+0+1+1)^{2}+(0+1+1+1)^{2}+5^{2}+3^{2}}+0+0 \\
& =7.376 \%
\end{aligned}
$$

Uncertainty $=100 \times(7.376 / 100)=7.38 \%$

The resulting CSA is $7.376 \%$ of the calibrated span of $100 \%$, namely, the instrument uncertainty for the high gamma alarm circuit is $7.38 \%$.

\subsubsection{Reference Document}

[1] IEEE Std 498-1980, Calibration and Control of Measuring \& Test Equipment Used! in Nuclear Power Generation Stations.

[2] SRS Quality Assurance Maiual $1 Q$ Procedure QAP 12-1 4/1/90, Control of: Measuring and Teat Equipment.

[3] SRS Technical Report WSRC-TR-94-031 Rev. 0, 2F Evaporator CP Class Instrumentation Uncerthinties Eyaluations.

[4] SRS Technical Report WSRC-TR-93-535 Rev.0, Evaluation of 242-HL Evaporato: Instrument Loop Setpoint Baris and Calibration Accuracy.

SRS HILWM Procedures:

[5] \#14368 Rev 1, Verification/Calibretion of MOORE Industries DCA Cument Alarm.

[6] 14401 Rev 1, Calibration of the ACROMAG Series $1600 \mathrm{~T}$ Transmitter.

[7] \#14487 Rev 1, Yerification/Calibration of HARSHAW Scintillation Detector.

SRS Drawings:

[8] W-701053 Rev. 152, Blde, 242-16H Stm Condenkate Pipine Diagram.

[9] M-M6-H-7849 Rev. 0, 2H Evaporator Steam System Pipine Diagram.

Vendor Literature:

[10] HARSHAW/FILTROL Manual, Scintillation Detector Operations.

[11] HARSHAW/FILTROL Manual, NV-25A High Voltage Power Supply.

[12] HARSHAW/FILTROL Manual, Model NA-23 Stabilized AMP/SCA.

[13] HARSHAW/FILTROL Manual, NC-22 Single Channel Pulse Height Analyzer.

[14] HARSHAW/FILTROL Manual, NR-25 Loparithmic-Linear Ratemeter.

[15] HARSHAW Dwg 62534 Rev 0, Project S-4171 SRP Block Diagram.

[16] ACROMAG Manual, Model 160T Millivolt/Current Transmitter.

[17] MOORE Industries Manual, Direct Current Alarm Unit Operations \#192-701 E. 
WSRC-TR-94-050 Rev. 0

Page 18 of 26

\subsection{Gamma Monitor Failure Alarm \& Interlock Circuit}

The gamma monitor failure alarm circuit is to alert the operator that the gamma monitor has failed and to trigger the diversion valve to transfer the condensate to a waste storage tank for reprocessing. The alarm circuit, referring to Fig. 2 loop diagram, consists of the scintillation detector RE-2022, the americium discriminating amplifier \& ratemeter RT2022B along with its associated E/I converter RY-2022B, the current switch RSH/L2022B, and the annunciator hi/lo alarm plate RAHL-2022. detector, the remainder of the circuit constitutes the process rack in the uncertainty evaluations.

- Scintillation Detector: HARSHAW/FILTROL MPF with 2" $\times 6$ " crystal - calibrated to $0-100 \%$ from pre-set known solution.(T)

- Spectro-signal Amplifier \& Ratemeter: HARSHAW/FILTROL NA-23, and NR-25 calibrated to 0-10 mv for 0-100 \%, 17,19]

- Millivolt/current Transmitter: ACROMAG Model 160T - calibrated to 4-20 ma for 0$10 \mathrm{mv}$.[0]

- Current Switch: MOORE Model DCA - calibrated to 0-100\% for 4-20 ma.[s]

- Annunciator Alarm Plate "CONDENSATE RADIATION MONITOR FAILURE FLASH TANK".

The alarm circuit is calibrated for 0 to $100 \%$ of gamma activity span. The spectro-signal amplifier \& ratemeter, in a NEMA 4 enclosure by the evaporator building $242-16 \mathrm{H}$, receives the scintillation detector input from a monitor container housing on the condensate transfer pipings. The $\mathrm{E} / \mathrm{I}$ converter in the same enclosure converts the ratemeter 0-10 mv output signal to 4-20 ma current signal and is wired to the high/low current switches located in the rear of the 1175B1 control panel in the control room bldg. $241-28 \mathrm{H}$. The energizing contact signal from the interposing relay is connected to the annunciator hi/lo alarm plate on the control panel and to the diversion solenoid valve on the condensate transfer pipings. $[8,9,15]$

\subsubsection{Measurement Uncertainties - in $\%$ of calibrated span}

Process Measurement Accuracy (PMA $=5 \%$ )

A $5 \%$ error tolerance is allowed in the SRS instrumentation practice. (4)

Primary Element Accuracy (PEA $=3 \%$ )

A $3 \%$ error allowance is assigned for the flow disturbance effect of the detector pot arrangement to the detector readings.

Sensor Calibration Accuracy (SCA $=0.5 \%$ )

The error tolerance is $0.5 \%$ per vendor device performance specifications. ${ }^{[10,11]}$ 
Sensor Measurement \& Teat Equipment (SMTE $=0.5 \%$ )

The standards lab M\&TE to the field M\&TE accuracy ratio will meet the IEEE Std 4981980(1) requirements of 4:1[2]. Therefore, the sccuracy of the standards lab M\&TE can be ignored and the uncertininty for the field M\&TE can be set based on the 1:1 ratio of the field M\&TE to process instrument calibration accuracy.

Sensor Drift (SD $=0.5 \%)$

The sensor stability is $0.5 \%$ error per year per vendor device performance specifications.

Sensor Temperature Effect (STE $=0 \%$ )

The ambient temperature has negligible effect on the sensor.

Sensor Preasure Effect (SPE $=0$ \%)

The static preasurn, has negligible effect on the sensor.

Rack Calibration Accuracy $\left(\mathrm{RCA}_{1}=1.6 \% ; \mathrm{RCA}_{2}=0.1 \%\right)$

$\mathrm{RCA}_{1}$ for the amp \& ratemeter is $1.6 \%$ and $\mathrm{RCA}_{2}$ for the $\mathrm{E} / \mathrm{I}$ converter is $0.1 \%$ per vendor device performance specifications. $(12,13,14,16)$

Rack Comparator Setting Accuracy (RCSA $=0.1 \%$ )

The error tolerance for the current switch is $0.1 \%$ per vendor device performance specifications. 117$]$

Rack M\&TE $\left(\mathrm{RMTE}_{1}=1.6 \% ; \mathrm{RMTE}_{2}=0.1 \%, \mathrm{RMTE}_{3}=0.1 \%\right.$ )

The uncertainty for the field M\&TE is set based on the 1:1 ratio of the field M\&TE to process instrument calibration accuracy.

Rack Drift $\left(R D_{1}=1.0 \%, R D_{2}=0.1 \%, R D_{3}=0.1 \%\right)$

$R D_{1}$ for the amp \& ratemeter is $1.0 \%, R_{2}$ for the $E / /$ converter is $0.1 \%$, and $R D_{3}$ for the current switch is $0.1 \%$ per vendor device performance specifications.

Rack Temperature Effect $\left(\mathrm{RTE}_{1}=0.5 \%, \mathrm{RTE}_{2}=0.3 \%\right)$

$\mathrm{RTE}_{1}$ for the ratemeter is $0.5 \%$, and $\mathrm{RTE}_{2}$ for the $\mathrm{E} / \mathrm{l}$ converter is $0.3 \%$ per vendor device performance specifications.

harsh Environmental Allowance (EA $=0$ \%)

The circuit is not subject to harsh environment.

BIAS - $0 \%$

No known bias exists. 


\subsubsection{Channel Statiatical Allowance}

The channel statistical allowance and the measurement uncertainties for the condensate gamma monitor failure alarm circuit are:

$$
\begin{aligned}
C S A & =\sqrt{5^{2}+3^{2}+(5+5+5)^{2}+0+0+(1.6+0+1.6+1)^{2}+(1+0+1+1)^{2}+(0+1+1+1)^{2}+5^{2}+3^{2}}+0+0 \\
& =7.376 \%
\end{aligned}
$$

Uncertainty $=100 \times(7.376 / 100)=7.38 \%$

The resulting CSA is $7.376 \%$ of the calibrated span of $100 \%$, namely, the instrument uncertainty for the gamma monitor failure alarm circuit is $7.38 \%$.

\subsubsection{Reference Document}

[1] IEEE Std 498-1980, Calibration and Control of Measurine \& Test Equipment Used in Nuclear Powrer Generntion Stations.

[2] SRS Quality Assurance Manual $1 Q$ Procedure QAP 12-1 4/1/90, Control of Menqurine and Teet Equipment.

[3] SRS Technical Report WSRC-TR-94-031 Rev. 0, 2F Evapomator CP Class Instrumentation Uncertainties Evaluations.

[4] SRS Technical Report WSRC-TR-93-535 Rev.0, Evaluation of 242-H Evaporator Instrument Ioos Setooint Basis and Calibration Accuracy.

SRS HILW Procedures:

[5] 14368 Rev 1, Yerification/Calibrtion of MOORE Industries DCA Current Alarm.

[6] 14401 Rev 1, Calibration of the ACROMAG Series $160 \mathrm{~T}$ Transmitter.

[7] "14487 Rev 1, Yerification/Calibration of HARSHAW Scintillation Detector.

SRS Drawings:

[8] W-701053 Rev. 152, Bldg, 242-16H Stm Condensate Pipine Diaram.

[9] M-M6-H-7849 Rev. 0, 2H Eyaporator Steam System Piping Diagram.

Vendor Literature:

[10] HARSHAW/FILTROL Manual, Scintillation Detector Operations.

[11] HARSBA W/FILTROL Manual, NV-25A High Voltage Power Supply.

[12] HARSHAW/FILTROL Manual, Model NA-23 Stabilized AMP/SCA.

[13] HARSEAW/FILTROL Manual, Model NM-4 Monitor.

[14] HARSHAW/FILTROL Manual, NR-25 Ioparithmic-Linear Ratemeter.

[15] HARSHAW Dwg 62534 Rev 0, Project S-4171 SRP Block Diagram.

[16] ACROMAG Manual, Model 160r Millivolt/Cument Transmitter.

[17] MOORE Industries Manual, Direct Current Alarm Unit Operations \#192-701 E. 


\subsection{Cerium Activity Reconder Circuit}

The condensate cesium activity recorder circuit is to provide the cesium activity readings and stripchart recording in the control room bldg. 241-28H. The recorder circuit, referring to Fig. 2 loop diagram, consists of the scintillation detector RE-2022, the cesium discriminating amplifier \& ratemeter RT-2022A along with its associated E/I converter RY-2022A, and the stripchart recorder RR-2022.(9] Except for the scintillation detector, the remainder of the circuit constitutes the process rack in the uncertainty evaluations.

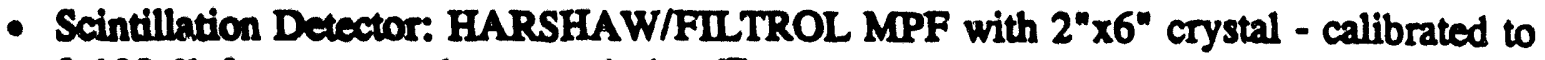
0-100 \% from pre-set known solution. (T)

- Spectro-signal Amplifier \& Ratemeter: HARSHAW/FILTROL NA-23, NC-22, and NR-25 - calibrated to 0-10 mv for 0-100\%, [7,15]

- Millivolv/current Transmitter: ACROMAG Model 160T - calibrated to 4-20 ma for 0$10 \mathrm{mv} \cdot[0]$

- Stripchart Recorder: L \& N Speedomax 1000 - calibrated to 0-100 \% for 4-20 ma.[5]

The recorder circuit is calibrated for 0 to $100 \%$ of gamma activity span. The spectrosignal amplifier \& ratemeter, in a NEMA 4 enclosure by the evaporator building 242-16H, receives the scintillation detector input from a monitor container housing on the condensate transfer pipings. The $E / I$ converter in the same enclosure converts the ratemeter 0-10 mv output signal to 4-20 ma current signal and is wired to the stripchart recorder located on the 1175B1 control panel in the control room bldg. 241-28H. [3,9,1s]

\subsubsection{Measurement Uncertainties - in \% of calibrated span}

Process Measurement Accuracy (PMA $=5 \%$ )

A $5 \%$ error tolerance is allowed in the SRS instrumentation practice. [4]

Primary Element Accuracy (PEA $=3 \%$ )

A $3 \%$ error allowance is assigned for the flow disturbance effect of the detector pot arrangement to the detector readings.

Sensor Calibration Accuracy (SCA $=0.5 \%$ )

The error tolerance is $0.5 \%$ per vendor device performance specifications. ${ }^{[10,11]}$

Sensor Messurement \& Test Equipment (SMTE $=0.5 \%$ )

The standards lab M\&TE to the field M\&TE accuracy ratio will meet the IEEE Std 4981980(1) requirements of 4:1[2]. Therefore, the accuracy of the standards lab M\&TE can be ignored and the uncertainty for the field M\&TE can be set based on the 1:1 ratio of the field M\&TE to process instrument calibration accuracy. 
Sensor Drit (SD $=0.5 \%)$

The sensor stability is $0.5 \%$ error per year per vendor device performance specifications.

Sensor Temperature Effect (STE $=0 \%$ )

The ambient temperature has negligible effect on the sensor.

Sensor Pressure Effect (SPE $=0 \%$ )

The static pressure has negligible effect on the sensor.

Rack Calibration Accuracy $\left(\mathrm{RCA}_{1}=1.6 \% ; \mathrm{RCA}_{2}=0.1 \%, \mathrm{RCA}_{3}=0.5 \%\right)$ $\mathrm{RCA}_{1}$ for the amp \& ratemeter is $1.6 \%, \mathrm{RCA}_{2}$ for the $\mathrm{E} / \mathrm{I}$ converter is $0.1 \%$, and $\mathrm{RCA}_{3}$ for the recorder is $0.5 \%$ per vendor device performance specifications. $(12,13,14,16]$ In addition, a 1 \% chart reading error allowance is assigned to the recorder (one half of the smallest chart scale).

Rack Comparator Setting Accuracy (RCSA $=0 \%$ )

There is no bistable element in the recorder circuit.

Rack M\&TE $\left(\mathrm{RMTE}_{1}=1.6 \% ; \mathrm{RMTE}_{2}=0.1 \%, \mathrm{RMTE}_{3}=0.5 \%\right)$

The uncertainty for the field M\&TE is set based on the 1:1 ratio of the field M\&TE to process instrument calibration accuracy.

Rack Drift $\left(R D_{1}=1.0 \%, R D_{2}=0.1 \%, R D_{3}=0.3 \%\right)$

$R D_{1}$ for the amp \& ratemeter is $1.0 \%, R_{2}$ for the $E / /$ converter is $0.1 \%$, and $R D_{3}$ for the recorder is $0.3 \%$ per vendor device performance specifications.

Rack Temperature Effect $\left(\mathrm{RTE}_{1}=0.5 \%, \mathrm{RTE}_{2}=0.3 \%, \mathrm{RTE}_{3}=0.5 \%\right)$

$\mathrm{RTE}_{1}$ for the ratemeter is $0.5 \%, \mathrm{RTE}_{2}$ for the $\mathrm{E} / \mathrm{I}$ converter is $0.3 \%$, and $\mathrm{RTE}_{3}$ is $0.5 \%$ per vendor device performance specifications.

harah Environmental Allowance (EA $=0 \%)$

The circuit is not subject to harsh environment.

BIAS - $0 \%$

No known bias exists.

\subsubsection{Channel Sntistical Allowance}

The channel statistical allowance and the measurement uncertainties for the condensate cesium activity recorder circuit are: 
WSRC-TR-94-050 Rev. 0

Page 23 of 26

$$
\begin{aligned}
c_{15} & =\sqrt{5^{2}+3^{2}+(5+5+5)^{2}+0+0+(1.6+0+1.6+1)^{2}+(1+0+1+1)^{2}+(5+0+5+3)^{2}+1^{2}+5^{2}+3^{2}+5^{2}}+0+0 \\
& =7.567 \%
\end{aligned}
$$

Uncertainty $=100 \times(7.567 / 100)=7.57 \%$

The resulting CSA is $7.567 \%$ of the calibrited span of $100 \%$, namely, the instrument uncertainty for the cesium activity recorder circuit is $7.57 \%$.

\subsubsection{Reference Document}

[1] IEEE Std 498-1980, Calibration and Control of Masuring \& Test Equipment Used in Nuclear Pover Genertion Stations.

[2] SRS Quality Assurance Manual 1Q Procedure QAP 12-1 4/1/90, Control of Measuring and Teat Equipment.

[3] SRS Technical Report WSRC-TR-94-031 Rev. 0, 2E Evaporator CP Class Instrumentation Uncertainties Evaluntions.

[4] SRS Technical Report WSRC-TR-93-535 Rev.0, Evaluntion of 242-H. Evapontor Instrument Loos setooint Basis and Calibration Accurecy.

SRS HILWM Procedures:

[5] "14401 Rev 1, Calibration of the ACROMAC Series 160T Transmitter.

[6] 14466 Rev 0, Yerification/Calibpation of Speedomax 1000 Series Recorder.

[7] \#14487 Rev 1, Verification/Calibration of BARSBAW Scintillation Detector.

SRS Drawings:

[8] W-701053 Rev. 152, Blde, 242-16H Stm Condensate Bipine Diapram.

[9] M-M6-H-7849 Rev. 0, 2B Eyaporrtor Steam System Piping Diapram. Vendor Literature:

[10] HARSHAW/FILTROL Manual (BPF 216611), Scintillation Detector Operations.

[11] HARSHAW/FILTROL Manual, NV-25A High Voltage Power Supply.

[12] HARSHAW/FILTROL Manual, Model NA-23 Stabilized AMP/SCA.

[13] HARSHAW/FILTROL Manual, NC-22, Single Channel Pulse Height Analyzer.

[14] HARSHAW/FILTROL Manual, NR-25 Logarithmic-Linear Ratemeter.

[15] HARSHAW Dwg 62534 Rev 0, Broject S-4171 SRP Block Diagram.

[16] ACROMAG Manual, Model 160T Millivolt/Cument Transmitter.

[17] LEEDS \& NORTHRUP Manual 277871, SPEEDOMAX 1000 Recorders. 
WSRC-TR-94-050 Rev. 0

Page 24 of 26

\subsection{Americium Activity Recorder Circuit}

The condensate americium activity recorder circuit is to provide the americium activity readings and stripchart recording in the control room bldg. 241-28H. The recorder circuit, referring to Fig. 2 loop diagram, consists of the scintillation detector RE-2022, the americium discriminating amplifier \& ratemeter RT-2022B along with its associated E/I converter RY-2022B, and the stripchart recorder RR-2022.91 Except for the scintillation detector, the remainder of the circuit constitutes the process rack in the uncertainty evaluations.

- Scintillation Detector: HARSHAW/FILTROL MPF with 2"x6" crystal - calibrated to 0-100 \% from pre-set known solution. (T)

- Spectro-signal Amplifier \& Ratemeter: HARSHAW/FILTROL NA-23 and NR-25 calibrated to 0-10 mv for 0-100\%, 7,15$]$

- Millivolt/current Transmitter: ACROMAG Model 160T - calibrated to 4-20 ma for 0$10 \mathrm{mv}$. (ต)

- Stripchart Recorder: L \& N Speedomax 1000 - calibrated to 0-100 \% for 4-20 ma. [\$]

The recorder circuit is calibrated for 0 to $100 \%$ of gamma activity span. The spectrosignal amplifier \& ratemeier, in a NEMA 4 enclosure by the evaporator building 242-16H, receives the scintillation detector input from a monitor container housing on the condensate transfer pipings. The $\mathrm{E} / \mathrm{I}$ converter in the same enclosure converts the ratemeter 0-10 mv output signal to 4-20 ma current signal and is wired to the stripchart recorder located on the 1175B1 control panel in the control room bldg. 241-28H.18,9,15]

\subsubsection{Measurement Uncertainties - in $\%$ of calibrated span}

Process Measurement Accuracy (PMA $=5 \%$ )

A $5 \%$ error tolerance is allowed in the SRS instrumentation practice. [4]

Primary Elemeit Accuracy (PEA $=3 \%$ )

A $3 \%$ error allowance is assigned for the flow disturbance effect of the detector pot arrangement to the detector readings.

Sensor Calibration Accuracy (SCA $=0.5 \%$ )

The error tolerance is $0.5 \%$ per vendor device performance specifications. ${ }^{110,11\}}$

Sensor Measurement \& Test Equipment (SMTE $=0.5 \%$ )

The standards lab M\&TE to the field M\&TE accuracy ratio will meet the IEEE Std 4981980(1) requirements of 4:1[1]. Therefore, the accuracy of the standards lab M\&TE can be ignored and the uncertainty for the field M\&TE can be set based on the 1:1 ratio of the field M\&TE to process instrument calibration accuracy. 
WSRC-TR-94-050 Rev. 0

Page 25 of 26

Sensor Drift (SD $=0.5 \%)$

The sensor stability is $0.5 \%$ error per year per vendor device performance specifications.

Sensor Temperature Effect (STE $=0 \%$ )

The ambient temperature has negligible effect on the sensor.

Sensor Pressure Effect (SPE = $0 \%$ )

The static preasure has negligible effect on the sensor.

Rack Calibration Accuracy $\left(\mathrm{RCA}_{1}=1.6 \% ; \mathrm{RCA}_{2}=0.1 \%, \mathrm{RCA}_{3}=0.5 \%\right)$

$\mathrm{RCA}_{1}$ for the amp \& ratemeter is $1.6 \%, \mathrm{RCA}_{2}$ for the $\mathrm{E} / \mathrm{I}$ converter is $0.1 \%$, and $\mathrm{RCA}_{3}$ for the recorder is $0.5 \%$ per vendor device performance specifications. ${ }^{112,13,14,16]}$ In addition, a 1 \% chart reading error allowance is assigned to the recorder (one half of the smallest chart scale).

Rack Comparator Setting Accuracy (RCSA $=0 \%$ )

There is no bistable element in the recorder circuit.

Rack M\&TE $\left(\right.$ RMTE $\left._{1}=1.6 \% ; \mathrm{RMTE}_{2}=0.1 \%, \mathrm{RMTE}_{3}=0.5 \%\right)$

The uncertainty for the field M\&TE is set based on the 1:1 ratio of the field M\&TE to process instrument calibration accuracy.

Rack Drift $\left(R D_{1}=1.0 \%, R D_{2}=0.1 \%, R D_{3}=0.3 \%\right)$

$R D_{1}$ for the amp \& ratemeter is $1.0 \%, R_{2}$ for the $E / I$ converter is $0.1 \%$, and $R D_{3}$ for the recorder is $0.3 \%$ per vendor device performance specifications.

Rack Temperature Effect $\left(\mathrm{RTE}_{1}=0.5 \%, \mathrm{RTE}_{2}=0.3 \%, \mathrm{RTE}_{3}=0.5 \%\right)$

$\mathrm{RTE}_{1}$ for the ratemeter is $0.5 \%, \mathrm{RTE}_{2}$ for the $\mathrm{E} / \mathrm{I}$ converter is $0.3 \%$, and $\mathrm{RTE}_{3}$ is $0.5 \%$ per vendor device performance specifications.

harsh Environmental Allowance (EA $=0$ \%)

The circuit is not subject to harah environment.

BIAS - $0 \%$

No known bias exists.

\subsubsection{Channel Statiotical Allowance}

The channel statistical allowance and the measurement uncertainties for the condensate americium activity recorder circuit are: 


$$
\begin{aligned}
C .1 & =\sqrt{5^{2}+3^{2}+(5+5+5)^{2}+0+0+(1.6+0+16+1)^{2}+(1+0+1+1)^{2}+(5+0+5+3)^{2}+1^{2}+5^{2}+3^{2}+5^{2}}+0+0 \\
& =7.567 \%
\end{aligned}
$$

Uncertainty $=100 \times(7.567 / 100)=7.57 \%$

The resulting CSA is $7.567 \%$ of the calibrated span of $100 \%$, namely, the instrument uncertainty for the americium activity recorder circuit is $7.57 \%$.

\subsubsection{Reference Document}

[1] IEEE Std 498-1980, Calibration and Control of Measuring \& Test Equipment Used in Nuclear Powrer Generation Stations.

[2] SRS Quality Assurance Manuai 1Q Procedure QAP 12-1 4/1/90, Control of Measurine and Test Equipment.

[3] SRS Technical Report WSRC-TR-94-031 Rev. O, 2F Evaporator CP Class Instrumentation Uncertainties Evaluations.

[4] SRS Technical Report WSRC-TR-93-535 Rev.0, Evaluntion of 242-H Evaporator Instrument Loces Setpoint Bacis and Calibration Accuracy.

SRS HILWM Procedures:

[5] "14401 Rev 1, Calibration of the ACROMAG Series $160 \mathrm{~T}$ Transmitter.

[6] 14466 Rev 0, Verification/Calibration of Speedomax 1000 Series Recorder.

[7] 14487 Rev 1, Verification/Calibretion of HARSHAW Scintillation Detector. SRS Drawings:

[8] W-701053 Rev. 152, B]dg, 242-16H Stm Condenknte Piping Diagmm.

[9] M-M6-H-7849 Rev. 0, 2B Evaporator Steam System Pipine Diagram. Vendor Literature:

[10] HARSHAW/FILTROL Manual (BPF 216611), Scintillation Detector Operations.

[11] HARSHAW/FILTROL Manual, NV-25A Bigh Voltnge Power Supply.

[12] HARSHAW/FILTROL Manual, Model NA-23 Stabilized AMP/SCA.

[13] HARSHAW/FILTROL Manual, Model NM-4 Monitor.

[14] HARSHAW/FILTROL Manual, NR-25 Logarithmic-Linear Ratemeter.

[15] HARSHAW Dws 62534 Rev 0, Broject S-4171 SRP Block Diagram.

[16] ACROMAG Manual, Model 160T Millivolt/Cument Transmitter.

[17] LEEDS \& NORTHRUP Manual 277871, SPEEDOMAX 1000 Recorders. 
Technical Report WSRC-TR-050 Rev. 0, "2H Evaporator CP Class Instrument Uncertainties Evaluations (U)", 2/8/94

G. T. Wright, 703-H

J. W. French, 703-H

T. M. Monahon, 703-H

V. G. Dickert, 703-H

R. L. Salizzoni, 707-H

R. W. Wilson, 707-H

E. R. Losure, 707-H

K. F. Lesko, 707-H

C. A. Polson, 707-H

M. A. Ceravolo, 707-H

S. Saunders, 707-H

A. Wooten, 992-1W

E. Hivang, 992-IW

W. F. Bates. 703-H

C. G. Kelly, 707-H

T. R. Jones, 707-H

R. A. Delcastilho, 707-H

J. E. Griffiths, 24l-102F

M. J. Rea, 707-H

P. W. Norris, 707-H

WME File Code 170.4, 703-H

Tech. Infor. Mgmt., 703-43A 

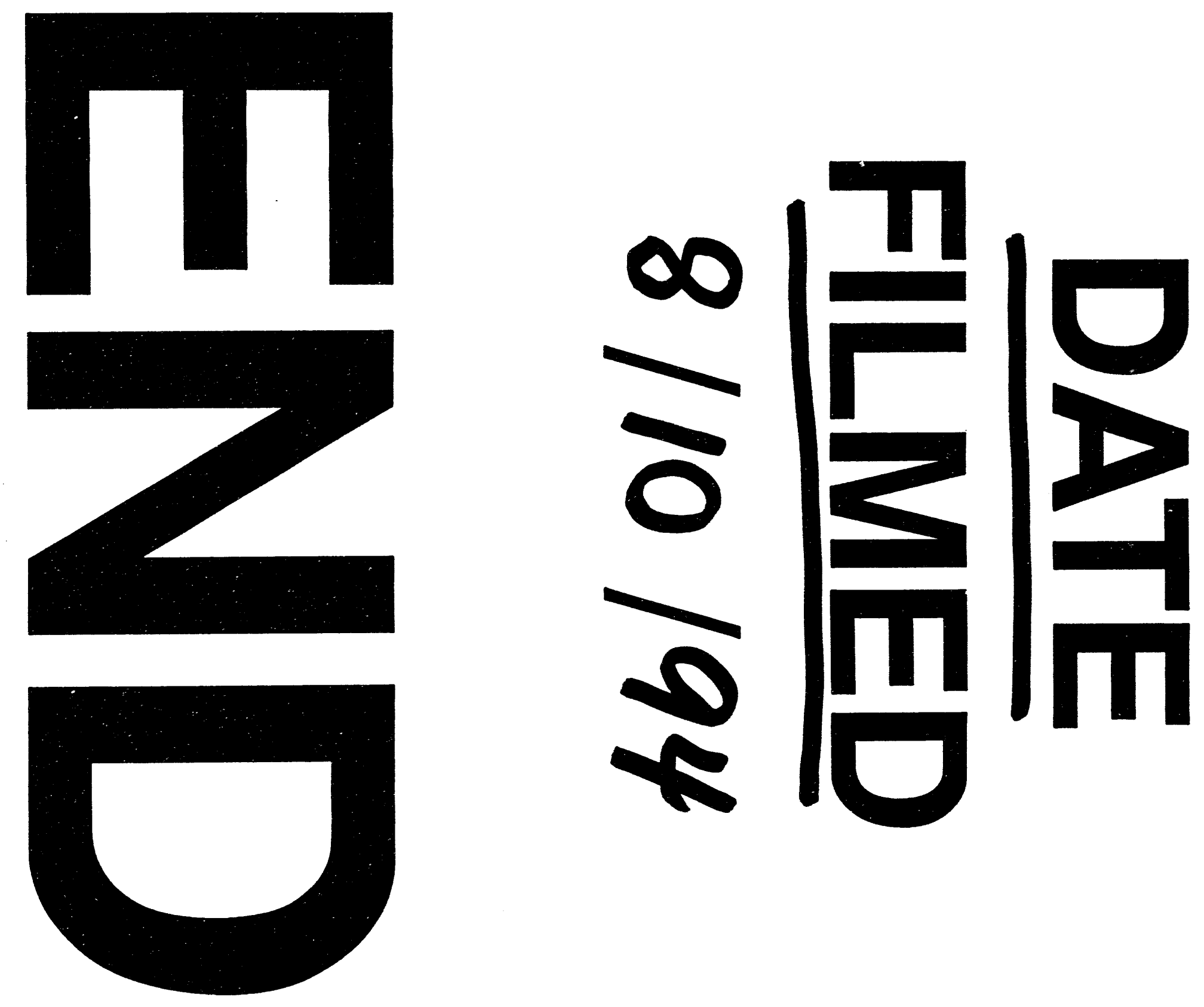
